\title{
Mismatch Repair Proteins (MLH1, MSH2, MSH6, and PMS2) Immunohistochemical Expression and Microsatellite Instability in Endometrial Carcinoma
}

\author{
Nour El Hoda S. Ismael ${ }^{1}$, Hala M. Naguib ${ }^{1}$, Suzan M. Talaat ${ }^{2 \star}$, Rasha F. Bakry ${ }^{3}$ \\ ${ }^{1}$ Department of Pathology, Faculty of Medicine, Cairo University, Egypt; ${ }^{2}$ Department of Pathology, Ahmed Maher Teaching \\ Hospital, Cairo, Egypt; ${ }^{3}$ Department of Pathology, Ahmed Maher Teaching Hospital, Cairo, Egypt
}

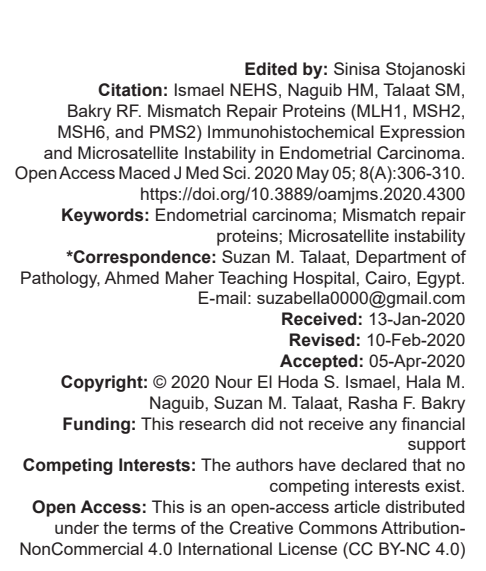

Introduction

Endometrial cancer (EC) is the fourth most common cancer in women ( $7 \%$ of cancers in women). In 2019 , there were estimated 61,880 new cases of and 12,160 deaths from EC [1]. EC is a disease of older, postmenopausal women and is uncommon in young women; $2 \%$ to $14 \%$ of endometrial carcinomas occur in women 40 years of age and younger. The most of these patients have an identifiable source of excess estrogen, while in a small subset the pathogenesis is related to mismatch repair abnormality and lynch syndrome (LC) [2].

In Egypt, primary malignant uterine neoplasms constituted $1.28 \%$ of total primary malignant neoplasms at National Cancer Institute and $22.83 \%$ of malignant neoplasms of female genital system. The primary malignant uterine neoplasms constituted $34.46 \%$ of all uterine lesions. The most common types were endometrioid adenocarcinoma
(59.58\%), followed by carcinosarcoma (10.71\%); serous adenocarcinoma (7.9\%); leiomyosarcoma $(6.2 \%)$; endometrial stromal sarcoma (4.69\%); and choriocarcinoma (3.94\%) [3].

Endometrial carcinomas are pathogenetically divisible into type 1 and type 2 tumors [4]. Type 1 tumors (Grade 1 and 2 endometrioid carcinoma) are the most common ECs. They may arise from complex atypical hyperplasia and are linked to excess of estrogen stimulation. As they are usually diagnosed at early stages, they present a relatively good prognosis. Type 2 tumors are the least common endometrial tumors. They include Grade 3 endometrioid tumors as well as tumors of non-endometrioid histology, and develop from atrophic endometrium. Type 2 tumors are less hormone sensitive. Since they are diagnosed in later stages, they are generally more aggressive [5].

Postmenopausal women with higher total concentrations of estrogens are at increased endometrial carcinoma risk as are women with polycystic ovary 
syndrome or estrogen producing ovarian tumors, earlier age at menarche, later age at menopause, nulliparity, or obesity. A positive family history of endometrial carcinoma, LC or Cowden syndrome elevates the risk of endometrial carcinoma [4].

LS or hereditary non-polyposis colon cancer is an autosomal dominant inherited disease caused by germline mutations in mismatch repair (MMR) genes. MLH1, MSH2, MSH6, and PMS2 mutation in this syndrome account for approximately 37, 41, 13, and $9 \%$, respectively. It is important to establish a diagnosis for this syndrome because of the associated elevated lifetime risk of developing cancers such as colorectal and ECs [6].

Among ECs, 2-5\% are likely to be associated with LC, in women either endometrial or colorectal carcinomas could be the presenting or sentinel cancer [7].

Since, LC confers a $14-54 \%$ risk of developing EC [7]. Thus, it is clinically relevant to identify LS women among EC patients to predict and prevents the development of other LS-associated cancers. It would also provide blood relatives an opportunity for genetic analysis and surveillance for LS-associated cancers. Each of the 4 MMR germline mutations leads to distinct molecular pathologies [8], and thus individuals carrying different mutations should not be regarded as suffering from the same disease. PMS2 germline mutation is associated with later onset, weaker family history, and a lower risk for cancer compared with other MMR germline mutations [9].

Clinical criteria to predict the likelihood of LC including Amsterdam, Bethesda, and Society of Gynecologic Oncology are not accurate and molecular testing of tumors is required to confirm or exclude LC [7].

Molecular screening of the tumors for the presence of MMR proteins in the nuclei using immunohistochemistry (IHC) is an alternative method of screening with sensitivity ranging between 86 and $100 \%$ [10].

There is a growing drive for universal screening of colorectal cancer (CRC) patients for LS [11], [12], [13]. Indeed, the National Institute of Health and Care Excellence in the United Kingdom has recently introduced a LS screening pathway for all CRC patients, alongside numerous institutions in the United States [14]. LS screening pathways utilize tumorbased testing IHC for MMR protein loss, microsatellite instability (MSI) testing or MLH1 (promoter methylation testing) to triage cases to undergo germline testing to identify a pathogenic variant in one of the MMR genes. Universal screening of EC patients for LS has been recommended by numerous experts and specialist societies [15]. Such practice has already been adopted in several cancer centers across the world [16], [17], [18].

\section{Methods}

Sixty cases of endometrial carcinoma covering different age groups were retrieved from the pathology department, Ahmed Maher Teaching Hospital, Cairo, Egypt, during the period from January 2013 to December 2016. Demographic and clinical data of the patients were collected from the hospital files.

Five um thick sections were cut from formalinfixed paraffin embedded tissue blocks and stained with hematoxylin and eosin for routine histopathological examination and determination of tumor type, grade, and stage.

Immunohistochemical staining was performed using immunostainer (Shandon Sequenza) using the labeled streptavidin biotin method with the following reagents: Diva Decloaker, pre-treatment antigen retrieval, (Biocare Medical Catalog number: DV2004 LX, MX), hydrogen peroxide block (Lab vision, USA, Catalog number: TA-060-HP), and Ultravision large volume detection system (Lab vision, USA, Catalog number: TP-060- HL) including Ultra V block, biotinylated goat anti-polyvalent plus (link) and streptavidin peroxidase plus (label), and DAB plus substrate system (Lab vision, USA, Catalog number: TA-060-HDX) including DAB plus chromogen and DAB plus substrate. The primary antibodies were PMS-2: A mouse polyclonal antibody (Biocare Medical Catalog number: PM 344 AA), MLH-1: A mouse monoclonal antibody (Biocare Medical Catalog number: PM 220 AA), MSH-6: A mouse monoclonal antibody (Biocare Medical Catalog number: PM 265 AA), and MSH-2: A mouse monoclonal antibody (Biocare Medical Catalog number: PM 219 AA).

Lymphocytes and/or stroma were used as internal positive controls [9], [19]. Sections of the same tissue were used following the same procedure with PBS used instead of the primary antibody as internal negative controls.

Complete absence of nuclear staining in the tumor cells is interpreted as loss of MMR protein expression [9], [20].

The presence of nuclear staining in tumor cells is good evidence of retained MMR protein, even if it is focal and weak staining. This has led to neglect staining pattern interpretation, with the exception of cases that show complete absence of nuclear staining [9].

Statistical analyses were performed using Statistical Package for the Social Science (SPSS 17.0 for windows; SPSS Inc, Chicago, IL, 2010). ChiSquare test was used to examine the relationship between two qualitative variables and between one quantitative and one qualitative variable. $p$ is significant when $\leq 0.05$. 


\section{Results}

Patient's ages ranged between 37 and 75 years with a mean age of $60.03 \pm 9.244$ years and median age is 60.8 years.

The most of the cases were endometrioid adenocarcinomas $(80 \%)$ including conventional endometrioid carcinoma (66.7\%), endometrioid with squamoid differentiation (8.3\%), and endometrioid villoglandular subtype $(5 \%)$. Twenty percent were non-endometrioid including serous carcinoma $(5 \%)$, carcinosarcoma $(5 \%)$, and mixed carcinoma $(10 \%)$. The majority of tumors were Grade II (40\%). About $95.8 \%$ of tumors were FIGO Stage I.

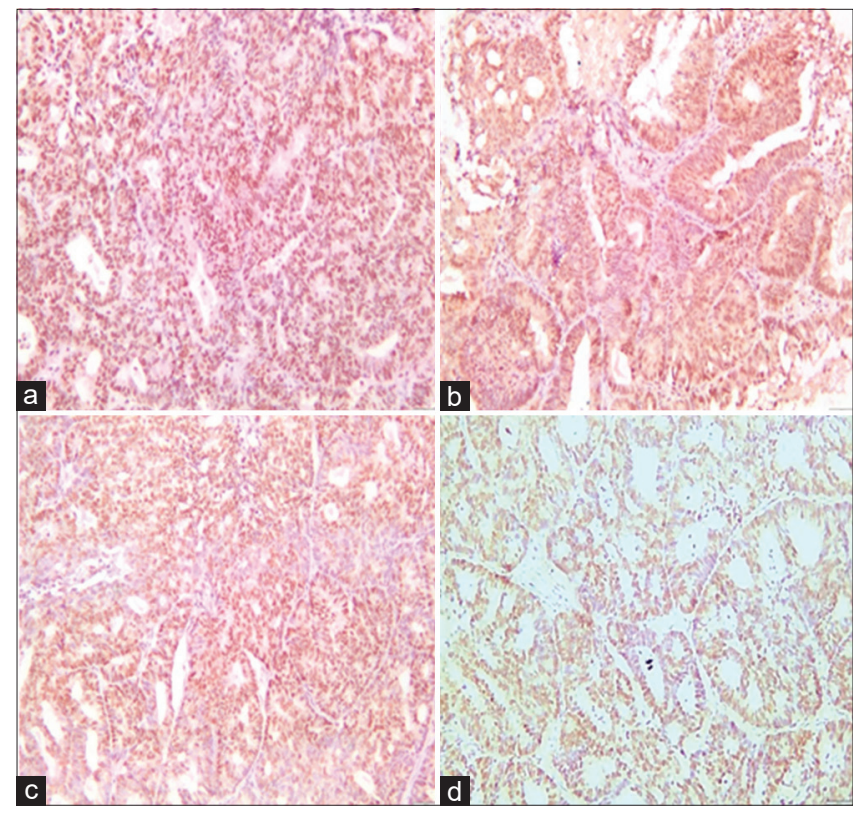

Figure 1: Endometrioid adenocarcinoma, Grade II, intact mutations in mismatch repair immunohistochemistry proteins, (a): MLH1 positive (×200), (b): PMS2 positive $(\times 200),(c):$ MSH2 positive $(\times 200)$, (d): MSH6 positive $(\times 200)$

Both MLH1/PMS2 were lost in $10 \%$ of cases and both $\mathrm{MSH} 2 / \mathrm{MSH} 6$ were lost in $3.3 \%$ of cases, while all MMR proteins were lost in $15 \%$ of cases. Isolated PMS2 loss was found in $15.0 \%$ of cases and isolated MSH6 loss was found in $3.3 \%$ of cases. MMR proteins were intact in $53.3 \%$ of cases.

There was statistically significant correlation between MMR IHC expression and tumor grade $(p=0.028)$. Intact MMR proteins profile was associated with the lower tumor grade (31.3\% were Grade 1 and $46.9 \%$ were Grade 2) (Figure 1). Combined loss of MLH1/PMS2, combined loss of MSH2/MSH6 (Figure 2) and isolated loss of PMS2 were also associated with the lower tumor grade while isolated loss of MSH6 was associated with high tumor grade (Figure 3) (Table 1).

No statistically significant correlation could be found between MMR proteins expression and age of the patients, tumor types, or FIGO stage.

\section{Discussion}

$\mathrm{EC}$ is the most common gynecological malignancy in high-income countries [5].

Mismatch repair proteins behave as tumor suppressors [17]. MMR loss results in a strong mutator phenotype known as $\mathrm{MSI}$, which is a hallmark of LC-associated cancers [21].

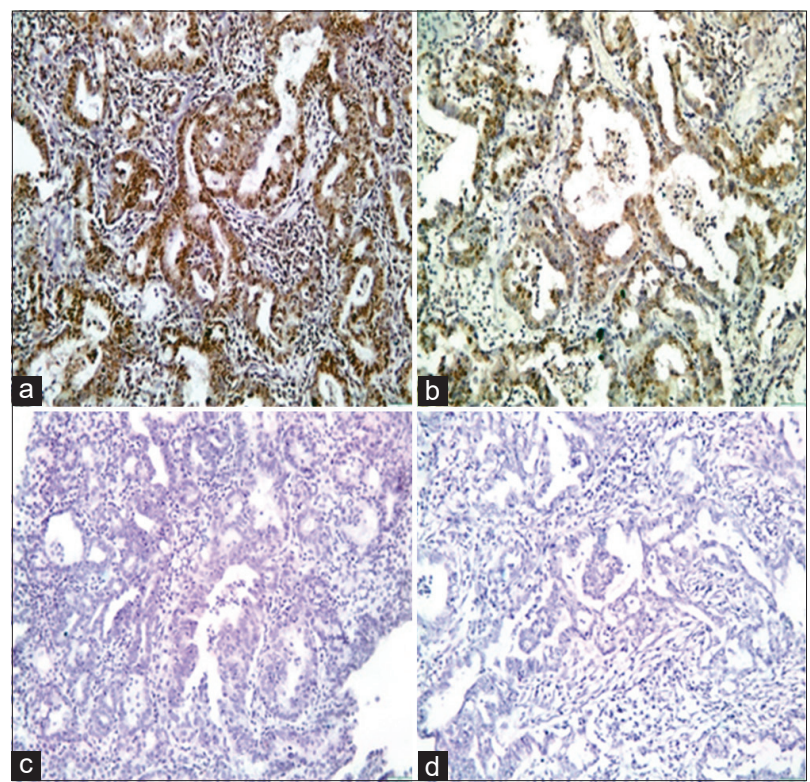

Figure 2: Endometrioid adenocarcinoma, Grade II, mutations in mismatch repair immunohistochemistry proteins, loss of $\mathrm{MSH}$ and MSH6, (a): MLH1 positive $(\times 200)$, (b): PMS2 positive $(\times 200)$, (c): $M S H 2$ negative $(\times 200),(d)$ : $M S H 6$ negative $(\times 200)$

Concerning the immunohistochemical expression of MMR proteins in endometrial carcinoma cases, all MMR proteins were intact in $(53.3 \%)$ of cases, MLH1/PMS2 loss was in (10\%) of cases, isolated PMS2 loss was in (15\%) of cases, MSH2/MSH6 loss was in

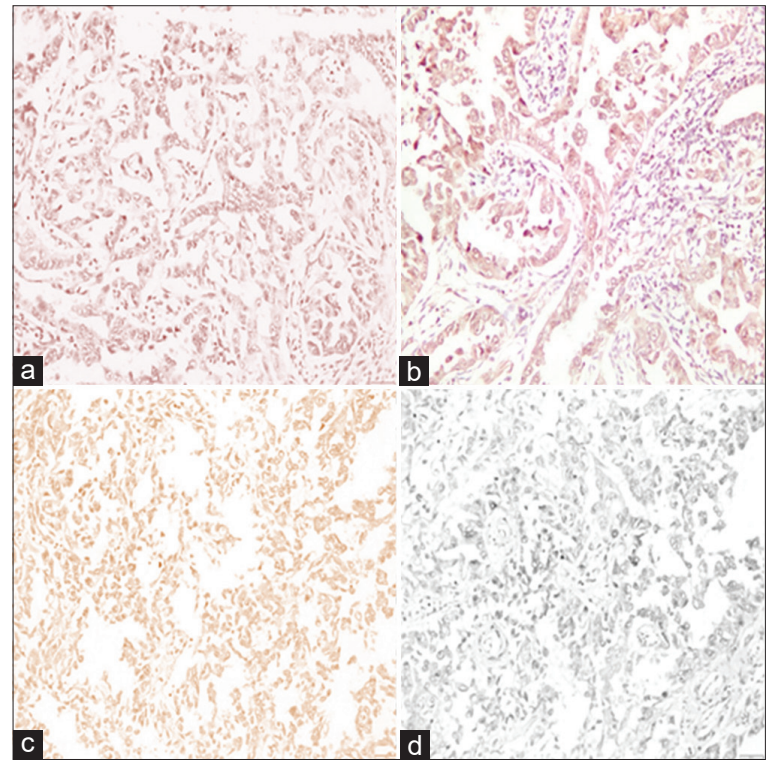

Figure 3: Serous endometrial adenocarcinoma, Grade III, FIGO Stage IB, isolated MSH6 loss, (a): MLH1 positive ( $\times 200),(b)$ : $P M S 2$ positive (×200), (c): MSH2 positive (×200), (d): MSH6 negative $(\times 200)$. 
(3.3\%) of cases, isolated loss of MSH6 was in 3.3\% of cases, and all MMR proteins were lost in (15\%) of cases. These results are near to those obtained by Egoavil et al. [22], Buchanan et al. [23], Ferguson et al. [24], Joehlin-Price et al. [25], and Dudley et al. [20].

Table 1: Relationship between MMR IHC expression and the tumor grades of EC cases

\begin{tabular}{llll}
\hline IHC panel & Grade I & Grade II & Grade III \\
\cline { 2 - 3 } $\begin{array}{l}\text { Count } \\
\text { (\% within IHC panel) }\end{array}$ & $\begin{array}{l}\text { Count } \\
\text { (\% within IHC panel) }\end{array}$ & $\begin{array}{l}\text { Count } \\
\text { (\% within IHC panel) }\end{array}$ \\
\hline No loss & $10(31.3)$ & $15(46.9)$ & $7(21.9)$ \\
MLH1/PMS2 loss & $1(16.7)$ & $5(83.3)$ & $0(0)$ \\
PMS2 loss & $6(66.7)$ & $1(11.1)$ & $2(22.2)$ \\
MSH2/MSH6 loss & $2(100)$ & $0(0)$ & $0(0)$ \\
MSH6 loss & $0(0)$ & $0(0)$ & $2(100)$ \\
All loss & $3(33.3)$ & $3(33.3)$ & $3(33.3)$ \\
Total & $22(100)$ & $24(100)$ & $14(100)$ \\
Sig. (p) & 0.028 & & \\
\hline \multicolumn{2}{l}{ MMR: Mutations in mismatch repair, EC: Endometrial cancer, IHC: Immunohistochemistry. }
\end{tabular}

There was statistically significant correlation between MMR IHC expression and tumor grade. This agreed with Clarke and Cooper [26] who found significant correlation between tumor grades and MMR IHC expression ( $p=0.0001)$ and $(p=0.009)$. respectively. Moreover. Hirasawa et al. [27] found that MSI high (MSI-H) was significantly correlated with high grade tumors (Grade 3 vs. Grades 1 and 2).

There was no statistically significant correlation between the patient's age of EC cases and MMR proteins expression. This was in agreement with the previous study of Mas-Moya et al. [28] but in contrast to Egoavil et al. [22] who found significant correlation between patient's age and MMR IHC expression and/ or MSI testing that the suspected hereditary condition was more frequently found in women younger than 50 years.

There was no statistically significant correlation between the histopathological types of endometrial carcinoma and MMR IHC expression which was in agreement with the study of Egoavil et al. [22], Joehlin-Price et al. [25], and Mas-Moya et al. [28].

There was no statistically significant correlation between the FIGO stage of endometrial carcinoma (EC) cases and MMR IHC expression the same as JoehlinPrice et al. [25] study.

MMR-IHC can be performed as part of a routine surgical pathology workflow, and validation is achievable for virtually any laboratory that processes IHC [19]. It can be used to evaluate MMR proteins expression and select patients for genetic testing. Loss or abnormal protein expression may be suggestive of LS [29].

In addition to influencing health-care decisions for individual cancer patients, a diagnosis of LS affects screening strategies for related family members. Involvement of genetic counselors is critical for advising both individual cancer patients and family members about the implications of testing [30].

\section{Conclusion}

There is a statistically significant correlation between the tumor grade of EC cases and the MMR IHC proteins expression and no correlation with the other analyzed clinicopathological parameters in this study. Hence, further studies on MMR proteins expression are recommended

\section{References}

1. Siegel RL, Miller KD, Jemal A. Cancer statistics, 2019. CA Cancer J Clin. 2019;69(1):7-34. PMid:30620402

2. Garg K, Soslow R. Endometrial carcinoma in women aged 40 years and younger. Arch Pathol Lab Med. 2014;138(3):335-42. PMid:24576029

3. Mokhtar N, Salama A, Badawy O, Khorshed E, Mohamed G Ibrahim $\mathrm{M}$, et al. Cancer pathology registry a 12-year registry 2000-2011. Natl Cancer Inst. 2016;13:192-208.

4. Kurman RJ, Carcangiu ML, Herrington CS, Young RH, editors WHO Classification of Tumours of Female Reproductive Organs. Lyon: IARC; 2014.

5. Amant F, Mirza MR, Koskas M, Creutzberg CL. Cancer of the corpus uteri. Int J Gynaecol Obstet. 2018;143(2):37-50. https:// doi.org/10.1002/ijgo.12612

PMid:30306580

6. Yokoyama T, Takehara K, Sugimoto N, Kaneko K, Fujimoto E, Okazawa-Sakai M, et al. Lynch syndrome associated endometrial carcinoma with MLH1 germline mutation and MLH1 promoter hypermethylation: A case report and literature review. BMC Cancer. 2018;18(1):576. https://doi.org/10.1186/ s12885-018-4489-0

PMid:29783979

7. Patil PA. Microsatellite instability testing in endometrial cancer-a short review. J Oncol Res Treat. 2018;3:2.

8. Cohen SA, Leininger A. The genetic basis of Lynch syndrome and its implications for clinical practice and risk management. Appl Clin Genet. 2014;7:147-58.

PMid:25161364

9. Kato A, Sato N, Sugawara T, Takahashi K, Kito M, Makino K et al. Isolated loss of PMS2 immunohistochemical expression is frequently caused by heterogenous MLH1 promoter hypermethylation in Lynch syndrome screening for endometrial cancer patients. Am J Surg Pathol. 2016;40(6):770-6. https:// doi.org/10.1097/pas.0000000000000606

PMid:26848797

10. Stewart AP. Genetic testing strategies in newly diagnosed endometrial cancer patients aimed at reducing morbidity or mortality from Lynch syndrome in the index case or her relatives. PLoS Curr. 2013;5. https://doi.org/10.1371/currents. eogt.b59a6e84f27c536e50db4e46aa26309c PMid:24056992

11. Vasen HF, Blanco I, Aktan-Collan K, Gopie JP, Alonso A, Aretz S, et al. Revised guidelines for the clinical management of Lynch syndrome (HNPCC): Recommendations by a group of European experts. Gut. 2013;62(6):812-23.

PMid:23408351

12. Provenzale D, Gupta S, Ahnen DJ, Bray T, Cannon JA 
Cooper G, et al. Genetic/familial high-risk assessment: Colorectal version 1.2016, NCCN clinical practice guidelines in oncology. J Natl Compr Canc Netw. 2016;14(8):1010-30. https:// doi.org/10.6004/jnccn.2016.0108 PMid:27496117

13. Rubenstein JH, Enns R, Heidelbaugh J, Barkun A, Clinical Guidelines Committee. American gastroenterological association institute guideline on the diagnosis and management of Lynch syndrome. Gastroenterology. 2015;149(3):777-82. https://doi.org/10.1053/j.gastro.2015.07.036 PMid:26226577

14. The National Institute for Health and Care Excellence. Molecular testing strategies for Lynch syndrome in people with colorectal cancer. Diagn Guidel. 2017;27:1-37. Available from: https://www. nice.org.uk/guidance/dg27. [Last accessed on 2019 May 10].

15. Crosbie EJ, Ryan NA, Arends M, Bosse T, Burn J, Cornes JM, et al. The Manchester international consensus group recommendations for the management of gynecological cancers in Lynch syndrome. Genet Med. 2019;21(10):2390-400. https:// doi.org/10.1038/s41436-019-0489-y

PMid:30918358

16. Batte BA, Bruegl AS, Daniels MS, Ring KL, Dempsey KM, Djordjevic $\mathrm{B}$, et al. Consequences of universal $\mathrm{MSI} / \mathrm{IHC}$ in screening endometrial cancer patients for Lynch syndrome. Gynecol Oncol. 2014;134(2):319-25. https://doi.org/10.1016/j. ygyno.2014.06.009 PMid:24933100

17. Frolova Al, Babb SA, Zantow E, Hagemann AR, Powell MA, Thaker $\mathrm{PH}$, et al. Impact of an immunohistochemistry-based universal screening protocol for Lynch syndrome in endometrial cancer on genetic counseling and testing. Gynecol Oncol. 2015;137(1):7-13. https://doi.org/10.1016/j.ygyno.2015.01.535 PMid:25617771

18. Dillon JL, Gonzalez JL, DeMars L, Bloch KJ, Tafe LJ. Universal screening for Lynch syndrome in endometrial cancers: Frequency of germline mutations and identification of patients with Lynch-like syndrome. Hum Pathol. 2017;70:121-8. https:// doi.org/10.1016/j.humpath.2017.10.022 PMid:29107668

19. Mills AM, Sloan EA, Thomas M, Modesitt SC, Stoler MH, Kristen A. Clinicopathologic comparison of Lynch syndromeassociated and "lynch-like" endometrial carcinomas identified on universal screening using mismatch repair protein immunohistochemistry. Am J Surg Pathol. 2016;40(2):155-65. https://doi.org/10.1097/pas.0000000000000544 PMid:26523542

20. Dudley B, Brand RE, Thull D, Bahary N, Nikiforova MN, Pai RK Germline MLH1 mutations are frequently identified in Lynch syndrome patients with colorectal and endometrial carcinoma demonstrating isolated loss of PMS2 immunohistochemical expression. Am J Surg Pathol. 2015;39(8):1114-20. https://doi. org/10.1097/pas.0000000000000425

\section{PMid:25871621}

21. Yamamoto $\mathrm{H}$, Imai $\mathrm{K}$. Microsatellite instability: An update Arch Toxicol. 2015;89(6):899-921. https://doi.org/10.1007/ s00204-015-1474-0

\section{PMid:25701956}

22. Egoavil C, Alenda C, Castillejo A, Paya A, Peiro G, SánchezHeras A, et al. Prevalence of Lynch syndrome among patients with newly diagnosed endometrial cancers. PLoS One. 2013;8(11):e79737. https://doi.org/10.1371/journal. pone. 0079737

PMid:24244552

23. Buchanan DD, Rosty C, Clendenning M, Spurdle AB, Win AK. Clinical problems of colorectal cancer and endometrial cancer cases with unknown cause of tumor mismatch repair deficiency (suspected Lynch syndrome). Appl Clin Genet. 2014;7:183-93. https://doi.org/10.2147/tacg.s48625

PMid:25328415

24. Ferguson SE, Aronson M, Pollett A, Eiriksson LR, Oza AM, Gallinger $\mathrm{S}$, et al. Performance characteristics of screening strategies for Lynch syndrome in unselected women with newly diagnosed endometrial cancer who have undergone universal germline mutation testing. Cancer. 2014;120(24):3932-9. https://doi.org/10.1002/cncr.28933 PMid:25081409

25. Joehlin-Price AS, Perrino CM, Stephens J, Backes FJ, Goodfellow PJ, Cohn DE, et al. Mismatch repair protein expression in 1049 endometrial carcinomas, associations with body mass index, and other clinicopathologic variables. Gynecol Oncol. 2014;133(1):43-7. https://doi.org/10.1016/j. ygyno.2014.03.435 PMid:24444820

26. Clarke BA, Cooper K. Identifying lynch Syndrome in Patients with endometrial carcinoma: Shortcomings of morphologic and clinical schemas. Adv Anat Pathol. 2012;19(4):231-8. https:// doi.org/10.1097/pap.0b013e31825c6b76 PMid:22692286

27. Hirasawa A, Aoki D, Inoue J, Imoto I, Susumu N, Sugano K, et al. Unfavorable prognostic factors associated with high frequency of microsatellite instability and comparative genomic hybridization analysis in endometrial cancer. Clin Cancer Res. 2003;9(15):5675-82 PMid: 14654551

28. Mas-Moya J, Dudley B, Brand RE, Thull D, Bahary N, Nikiforova $\mathrm{MN}$, et al. Clinicopathological comparison of colorectal and endometrial carcinomas in patients with lynch-like syndrome versus patients with lynch syndrome. Hum Pathol. 2015;46(11):1616-25. https://doi.org/10.1016/j. humpath.2015.06.022 PMid:26319271

29 Bartosch C, Pires M, Jeronimo C, Lopes JM. The role of pathology in the management of patients with endometrial carcinoma. Future Oncol. 2017;13(11):1003-20. https://doi. org/10.2217/fon-2016-0570 PMid:28481146

30. Mills AM, Liou S, Ford JM, Berek JS, Pai RK, Longacre TA Lynch syndrome screening should be considered for all patients with newly diagnosed endometrial cancer. Am J Surg Pathol. 2014;38(11):1501-9. https://doi.org/10.1097/ pas. 0000000000000321

PMid:25229768 